\title{
Relationship of modern and traditional schools of chinese medicine: need it remain hostile?
}

\begin{abstract}
Summary
Ninety per cent of acupuncturists in the world pay lip service at least to Traditional Chinese Medicine (TCM), a system that is similar in many ways to our own pre-Renaissance medical thinking. It is one of the few surviving forms of ancient medicine. So we do need to know something of its history, its way of thought and terminology. Lu \& Needham ${ }^{1}$ described the extraordinary evolution of Chinese medicine from ancient observation to modern physiological explanations such as the mechanisms of referred pain. They pointed out a number of misunderstandings in the West about acupuncture: it has nothing to do with occult influences, psychic powers or parapsychology and does not deserve the praises of people who believe these things; furthermore, it does not depend entirely on suggestion or hypnotic phenomena and nowadays is not in conflict with the findings of Western medicine. There is no need for a warring relationship between the past and the present.
\end{abstract}

Volume 7 Issue 2 - 2017

\author{
Alexander Macdonald \\ Bristol BS8 IBA, UK \\ Correspondence: Alexander Macdonald, Bristol BS8 IBA, UK, \\ Email alexmac@lineone.net
}

Received: February 14, 2017| Published: May 30, 2017

\section{A history of events}

It was rare and brave of $\mathrm{Lu}$ and Needham ${ }^{1}$ to consider the history of so contentious a subject as the development of modern acupuncture in such detail. Although Needham and Lu 1975 fully admitted the difficulty Western scholars have in translating ancient Chinese technical medical terms, they skated elegantly over the space that lies between the 'essentially mediaeval' thinking of the traditional practitioners of China and the modern methods of Western-inspired investigators who describe the nervous system's responses to the insertion of needles. Neither side should be insulted or compared: should be congratulated for their attempts to explain the manner in which many diseases may be treated by applying the noxious stimulus of a needle (acupuncture) or heat (moxibustion). Now that laboratories have begun to explore the subject in a scientific manner, a number of rational explanations have been cited for many of its actions and its recent and perhaps most spectacular phenomenon - the relief of pain during major surgery in man and animals. One can now explain how it is that a man can have a tumour cut from his jaw with a thread-saw while remaining conscious, yet showing no signs of pain: his only apparent relief being provided by electrical stimulation of two needles - one inserted into his neck and the other into his head. As a result of Western and Chinese work we have an explanation: acupuncture stimulates the central nervous system to produce certain morphinelike substances (endogenous opioids) that may on occasion (certainly not every occasion) be sufficient to provide the pain relief required to sustain major surgery in relative comfort. The Chinese are now able to admit that an undisclosed number of patients who were not expected to do well did not receive acupuncture during surgery and were given conventional forms of anaesthesia instead; therefore earlier reports of $75 \%$ success rates were the percentage of the chosen few rather than the population as a whole. We can still learn from the scholarly Chinese conjectures about the subtle interplay of influences arising from the various internal organs and the ever-changing phenomena existing in the outside world. In many ways, before the 16th Century at least, the Chinese had an unrivalled knowledge of the mechanisms of the body. It is possible, for example, that William Harvey's Excertatio de motu cordis et sanguinis, which demolished traditional European beliefs with his notion that blood flowed in a true circulation, was written in the knowledge that this was standard doctrine in China a millennium before him. Acupuncture was developed in a civilisation quite different from our own, a culture whose medical literature was two thousand years old at a time when Western scientific attitudes to medicine were just beginning to be fashioned.

In the days before history was recorded in China, medicine may have been practised by goatherds who discovered sharp pieces of flint could be used to relieve various illnesses; they may also have set fire to herbs and deliberately applied this heat to the skin to achieve the same effect. Some of the earliest writings in China describe a system based on these early observations. Here philosophers were interested in man's place in the universe. They described how the same laws they saw governing the world around them determined man's health. Indeed, they concentrated on keeping people healthy wherever this was possible. When a person actually became ill, then the most solemn discourse on the possible causes were described in detail in elegant works that may have been written as long ago as the second or third centuries BC. However, the chief milestone today is that we realize acupuncture produces its effects through the nervous system. This is probably but the beginning of a new chapter in an old story.

\section{Natural skepticism}

It is the custom for Western practitioners to be sceptical about Traditional Chinese Medicine (TCM). A physician fromMontpellier, journeying into China in 1767, said: 'Praise be to God not to have shown me one confirmation of the Chinese methods in my travels.' He was delighted not to have to re-think all he had learned in medical school. A Western medical student can state quite bluntly that never once during his arduous studies has he ever seen evidence described by traditional acupuncturists as an important arrangement of channels within the body.

Some anatomical studies were performed in Ancient China, particularly on the battlefield. There were legends that on occasion the bodies of executed bandits were examined in some detail by doctors of the day and recorded in drawings by the coroner. ${ }^{2}$ In this way the lengths of the larger blood vessels may have been measured, and the circulation of the blood through organs of the body was described in China two thousand years before this idea was considered in Europe. As the microscope had not been invented in China or permission granted for the study of anatomy in general, detailed anatomical studies performed in Europe during the last four hundred years were not possible in China until the early 1920's particularly as the Chinese 
believed their bodies belonged to their ancestors and had to be returned to them intact. In 1861, an experienced missionary surgeon, William Lockhart wrote: 'At present there are no colleges or schools in the Country excepting the Imperial College at Peking for the use of his Majesty and high officers'; 'the knowledge of anatomy and surgery in ancient Greece and Rome was much superior to anything now in India and China'; 'anatomy is totally interdicted both by law and public opinion'; 'there is no distinction between arteries and veins - no knowledge of the heart's proper function'; 'they have a pulse for every organ but the brain'; 'everything, even the most inscrutable and mysterious is explained by the Yin and the Yang, the hot and the cold, the dry and the moist, the superior and inferior influences!'; and 'any man, however, may practise medicine, and thousands do so, with the slender knowledge which books afford, or by the exercise of their common-sense, which provides a safer guide, and brings persons occasionally into notoriety, and also a good income'. In the 1920 's, for the first time in China, bodies were dissected in anatomy departments of the new medical schools pioneered by missionary societies. They were the bodies of executed criminals. A professor of anatomy complained they had been executed in such a clumsy way his students could not study the neck region properly. The local warlord pronounced that in future the prisoners would be brought to the department and be executed in any way he wished.

Since 1920 no Chinese scientist has reported any evidence of the existence of a discrete channel system or other unique structure within the tissues that would explain the pathways of the 'meridians' or form the substance of 'acupuncture points'. However in the past five decades, in other countries, sophisticated investigations involving electrical impedance measurements, thermography, advanced tissue staining techniques and injection of radioactive tracers have revealed phenomena that have been attributed to a hitherto unknown system of communication within the tissues $;{ }^{3}$ but it is not likely that hundreds of years ago, without access to equipment of this kind, the Chinese savants could have arrived at these observations. Meanwhile, in China the view is that the explanation for acupuncture lies in the nervous system. As the neurophysiologist, Professor $\mathrm{Han}^{4}$ writes, 'The search for the anatomical and histological substrate of the "channel" or "meridian" has continued for decades. Evidence for the involvement of the nervous system is sufficient and straightforward'.

\section{Traditional chinese medicine (TCM) falls out of favour}

The Chinese themselves have attacked traditional Chinese medicine. In the early part of the $20^{\text {th }}$ Century, even its stoutest defenders had to admit it had fallen into the wrong hands; there were large numbers of lower-grade doctors or apothecaries, itinerant medicine peddlers, and charlatans of every description - so much so as Lehmann ${ }^{5}$ describes, in 1822 the Ching Emperor Daoguang decreed that as acupuncture and moxibustion was not suitable for an Emperor it would be banned for ever from the Imperial medical academy. Nevertheless the practice of acupuncture continued. Indeed, Dr William Sewell described his experiences during the 1920's when he first arrived in China as a missionary medical lecturer. He saw a practitioner take a long needle out of one patient, wipe it on the side of his boot and polish it on his lapel before plunging it through layers of clothing into another patient. What was perhaps even more dangerous was the habit of consulting one traditional doctor after another - to collect herbal remedies that each had prescribed and consume them all simultaneously: the hospitals admitted many patients dying from herbal overdoses. 60,000 people died in Manchuria of a plague between 1910 and 1911. Eighty traditional physicians were specially selected to control the plague. They all died of it themselves. The only person who was able to help was a young Cambridge-trained doctor, Wu Lien-te, who used his scientific knowledge to direct the sanitary and public health measures required to prevent the plague from spreading further. This made a great impression on the authorities. The venerable and hitherto traditionally oriented Viceroy of Manchuria, Hai Liang, remarked: 'The lessons taught us by this epidemic have been great and have compelled several of us to revise our former ideas if railways, telegraphs, electric lights, and other modern inventions are indispensable to the material welfare of this country, we should also make use of the wonderful resources of Western medicine for the benefit of our people'. At the end of the First World War, the new generation of Chinese intellectuals was Westernoriented; they denounced many of their own traditions. Ch'en Tuhsiu had harsh words to say about traditional medical beliefs: 'Our doctors don't know science. ${ }^{6}$ They don't understand human anatomy and what is more don't analyse the nature of medicine. As for bacteria and communicable diseases, they haven't heard of them. They only talk about the five elements, their production and elimination, heat and cold, yin and yang, and prescribe medicine according to old formulae. All these nonsensical ideas and reasonless beliefs must be cured by the support of science. Another intellectual, Lu Hsün, wrote short essays ridiculing traditional medical ideas, and succeeded in painting a horrifying picture of the superstitions that prevailed. In his story Tomorrow, he describes the traditional physician at work: 'He is ignorant and callous, brushing off the anxious queries of a widowed mother with empty phrases about "obstruction of the digestive tract" and "fire overpowering" in order to pocket her fee and be rid of her. After taking the prescription, the woman's son dies'.

\section{Swing back into favour}

Until recent times the only medicine known to most of China was traditional. In 1949, ninety-five percent of Chinese doctors were of the traditional school. By the 1960's, however, less than half the Chinese doctors were traditional; yet their legacy of two millennia has persisted, and Chinese patients continue to demand traditional medicine. An observer in the 1980's of a Canton rural commune noted that the proportions of patients requesting traditional as opposed to modern medicine were three to one. It is probable that the Chinese belief in their traditional remedies has ensured that, for every patient it may have blundered with, it has comforted several others. Even some of the most ardent of modern physicians were forced to use traditional remedies for their own afflictions. Dr Hu Shih addressed doctors who had just qualified at his own University of Peiping: 'The old-style medicine will sooner or later be replaced by the modern.' However, in the days before insulin was employed, he became ill himself with diabetes: he consulted a traditional doctor, Lu Chung-an, who provided relief with herbs. ${ }^{7}$

\section{The forced marriage}

The communist victory in 1949 presented both types of doctor with new problems. Traditional doctors were suspect, as their practice relied on a philosophy of China's feudal past. At first, the Communist radicals planned to do away with traditional medical practice and modernize it; but they had become accustomed to the effects of traditional remedies during their long struggle to power, especially as the Japanese and Kuomintang blockade prevented them from importing modern drugs. Also the actual number of modern doctors in 1949 was pitifully inadequate - a mere 10,000 for a population of 550 million people; whereas there were 500,000 traditional doctors. Chairman Mao Tse-Tung had given China's medical situation a great 
deal of thought. In 1944 he cited the following example: 'Among the $1,500,000$ people of the Shensi-Kangsu Ningsia Border Region, there are more than 1,000,000 illiterates, there are 2,000 practitioners of witchcraft, and the broad masses are still under the influence of superstition the human and animal mortality rates are both very high. . . In such circumstances, to rely solely on modern doctors is no solution. Of course, modern doctors have advantages over doctors of the old type, but if they do not concern themselves with the sufferings of the people, do not unite with the thousand and more doctors and veterinarians of the old type in the Border Region and do not help them to make progress, then they will actually be helping the witch doctors. There are two principles for the united front: the first is to unite, and the second is to criticize, educate and transform'. From 1949 onwards, 'united' clinics or hospitals were organised to foster the new relationship between traditional and modern practices. Patients fees were pooled to pay the doctors' salaries and other expenses. ${ }^{8}$

Traditional doctors were being asked not only to give up their private practice but also to share their fiercely guarded secrets; for they still held the feudal notion, 'You must not crack the vase that holds the rice'. Despite their co-operation, traditional doctors were still excluded from large urban hospitals; they were only made use of in rural areas where there was a desperate shortage of modern doctors. Thus modern medicine was definitely the dominant partner in its 'forced marriage' with traditional medicine. Naturally, the traditional doctors smarted under the unconcealed contempt of their Western-trained colleagues; but it did not take long before they exacted satisfying reprisals. In 1955, the Ministry of Health was attacked for its lack of appreciation of traditional practices. Several senior modem physicians were openly criticised for their overbearing Western attitudes and lack of concern for the mass of their patients. The modern doctor's insistence that he had been trained as an expert irritated the communist authorities: whereas the traditional doctor persecuted in the past by the intellectuals, was exalted for his lack of demands for status or resources. The Press, while castigating modern doctors, released pictures of the white-bearded venerable traditional doctor - showing that the authorities had adopted a loving care for the neglected popular elements in the old culture. People remembered the days before the Second World War when the Rockefeller Foundation financed the Peking Union Medical College. Here graduates were automatically recognised by the West, and encouraged to travel to the States for further training. They practised from the large cities and amassed considerable fortunes: they failed to treat the mass of the population in the countryside. Other accusations were thrown at the American adventure into Chinese medicine - charity patients were subjected to barbarous medical experiments, and when under attack, local warlords were offered sanctuary in the hospitals for non-medical reasons.

\section{Compromise}

The authorities found a way out of the quagmire; they accorded both forms of practice equal status. In 1955, Peking Medical College founded the Chinese Traditional Medical Research Institute; at the same time Shanghai Medical College started the Acupuncture Research Institute. By 1959, twenty-seven similar research centres were funded throughout the country to encourage traditional doctors to undertake scientific research into their work. Meanwhile the most important decision was to appoint traditional practitioners to the staffs of hospitals in the large cities. Since the 1950's all medical students have to study both modern and traditional medicine. Those students who wish to practise traditional medicine have to study the relevant modern knowledge of anatomy, physiology, and so on; while those who wish to practise modern medicine have to attend lectures on various traditional aspects. Premier Chou en-Lai summed up his administration's attitude: 'Make the Motherland's medical heritage serve socialism.'

\section{Conclusion}

The traditional and modern attitudes to medicine have not been fused. Their bases of thought and expression are clearly not the same: for instance, the very word 'disease' has modern and traditional descriptions that are quite different. Therefore, the two types of doctor diagnose disease and assess its progress and treatment in very different ways. There is still a fundamental clash between the two schools of medicine; for doctors of one school pay scant regard to the other once they are qualified. The fiery nature of the argument between the traditional Chinese and Western schools of medicine would become cooler when it is remembered how their different understandings of disease arose. The traditional texts were written by doctors who were forced to rely on their unaided senses in their examination of patients. They were unaware of the cellular structure of the body, and had none of the modern understanding of the nervous system; they did not possess microscopes or any of the other apparatus so essential to modern medical studies. Nevertheless, they made some important observations; in the past three decades, a great deal of scientific work to separate the wheat from the chaff has been funded both in China and in the West. Those who ignore or are unable to understand scientific work and prefer to accept all the traditional Chinese medical concepts as being utterly true are as blinkered as those who reject them totally without first understanding how it was that these ideas and thoughts arrived in practitioners' minds.

\section{Acknowledgments}

None.

\section{Conflicts of interest}

Author declares there are no conflicts of interest.

\section{Funding}

None.

\section{References}

1. Lu GD, Needham J. Celestial Lancets: a History \& Rationale of Acupuncture \& Moxa. USA: Cambridge University Press; 1980.

2. Schnorrenberger CC. Chen-Chiu The original Acupuncture, a New Healing Paradigm. Wisdom Publications, Boston, USA. 2003.

3. Longhurst JC. Defining meridians: a modern basis of understanding. Journal of Acupuncture and Meridian Studies. 2010;3(2):67-74.

4. Han JS. Acupuncture analgesia: areas of consensus and controversy. Pain. 2011;152(3):S41-S48

5. Lehmann H. Acupuncture in ancient China: how important was it really? J Integr Med. 2013;11(1):45-53.

6. Kendall DE0.Dao of Chinese Medicine: Understanding and Ancient Healing Art. Oxford University Press, Hong Kong, China. 2011.

7. Lockhart W. The Medical Missionary in China: a Narrative of Twenty Years' Experience. London: Hurst and Blackett; 1861.

8. Needham J, Lu GD. Problems of translation and modernization of ancient Chinese technical terms: Manfred Porkert's interpretation of terms in ancient and medieval Chinese natural and medical philosophy. Annals of Science. 1975;32(5):491-502. 